
EFFICACY DATA FROM THE EUSTAR NETWORK

M. Elhai ${ }^{1,2}$, O. Distler ${ }^{3}$, V. Smith ${ }^{4}$, M. Matucci-Cerinic ${ }^{5}$, J.J. Alegre-Sancho ${ }^{6}$, M. $^{-}$ E. Truchetet ${ }^{7}$, Y. Braun-Moscovici ${ }^{8}$, F. lannone ${ }^{9}$, F. Chotchaeva $^{10}$, A. Lescoat ${ }^{11}$, E. Siegert ${ }^{12}$, I. Castellví ${ }^{13}$, P. Airò ${ }^{14}$, S. Vettori ${ }^{15}$, E. Hachulla ${ }^{16}$, A. Erler $^{17}$, L. Ananieva ${ }^{18}$, M. Krusche ${ }^{19}$, F. López-Longo ${ }^{20}$, J. Distler ${ }^{21}$, N. Hunzelmann ${ }^{22}$, A.M. Hoffmann-Vold ${ }^{23}$, V. Riccieri' ${ }^{24}$, V. Hsu ${ }^{25}$, M. Pozzi ${ }^{26}$, C. Ancuta ${ }^{27}$, E. Rosato ${ }^{28}$, C. Mihai ${ }^{29}$, M. Kuwana ${ }^{30}$, Y. Allanore ${ }^{31}$, on behalf of EUSTAR. ${ }^{1}$ Rheumatology $A$ department, Paris Descartes University, Cochin Hospital; ${ }^{2}$ INSERM U1016, Cochin Institut, Paris, France; ${ }^{3}$ Department of Rheumatology, University Hospital Zurich, Zurich, Switzerland; ${ }^{4}$ Department of Rheumatology, University of Ghent, Ghent, Belgium; ${ }^{5}$ Department of Experimental and Clinical Medicine, Section of Internal Medicine and Division of Rheumatology, Azienda Ospedaliero-Universitaria Careggi (AOUC), University of Florence, Florence, Italy; ${ }^{6}$ Hospital Universitario Dr Peset, Valencia, Spain; ${ }^{7}$ Rheumatology department, Bordeaux University Hospital, Bordeaux, France; ${ }^{8}$ B. Shine Rheumatology Unit, Rambam Health Care Campus, The Rappaport Faculty of Medicine, Technion, Haifa, Israel; ${ }^{9}$ nterdisciplinary Department of Medicine-Rheumatology Unit, Policlinico, University of Bari, Bari, Italy, ${ }^{10}$ Clinic of Nephrology, Internal and Occupational Diseases, Sechenov First Moscow State Medical University, Moscow, Russian Federation; ${ }^{11}$ Department of Internal Medicine, CHU Rennes, Rennes, France; ${ }^{12}$ Department of Rheumatology, Charité University Hospital, Berlin, Germany; ${ }^{13}$ Hospital de la Santa Creu i Sant Pau, Barcelona, Spain; ${ }^{14}$ UO Reumatologia ed Immunologia, Clinica Spedali Civili Brescia, Brescia; ${ }^{15}$ Department of Clinical and Experimental Medicine, 'F-Magrassi' II, Naples, Italy, ${ }^{16}$ Department of Internal Medicine, Hôpital Claude Huriez, University Lille Nord-de-France, Lille, France; ${ }^{17}$ Division of Rheumatology Department of Medicine III, Technical University of Dresden, Dresden, Germany; ${ }^{18}$ VA Nasonova Institute of Rheumatology, VA Nasonova Institute of Rheumatology, Moscow, Russian Federation; ${ }^{19}$ Abteilung für Rheumatologie, Immunologie, Nephrologie, Asklepios Klinik Altona, Hamburg, Germany, ${ }^{20}$ Servicio de Reumatología, Hospital General Universitario Gregorio Marañón, Madrid, Spain; ${ }^{21}$ Department of Internal Medicine 3, University Hospital Erlangen, Erlangen; ${ }^{22}$ Department of Dermatoloy, University Hospital Cologne, Cologne, Germany; ${ }^{23}$ Department of Rheumatology, Rikshospitalet University Hospital, Oslo, Norway; ${ }^{24}$ Department of Internal Medicine and Medical Specialities, 'Sapienza' University of Rome, Rome, Italy; ${ }^{25}$ UMDNJ-Scleroderma Program Clinical Research Center - Robert Wood Johnson Medical School, New Brunswick, USA; ${ }^{26}$ Dipartimento di Medicina, Ospedale San Gerardo, Monza, Italy, ${ }^{27}$ Clinical Rehabilitation Hospital Rheumatology and Rehabilitation 'Grigore T. Popa' University of Medicine and Pharmacy, Iasi, Romania; ${ }^{28}$ Centro per la Sclerosi Sistemica -Dipartimento di Medicina Clinica, Università La Sapienza, Policlinico Umberto I, Roma, Italy; ${ }^{29}$ Department of Internal Medicine and Rheumatology Clinic, Ion Cantacuzino Clinical Hospital, Carol Davila University of Medicine and Pharmacy, Bucharest, Romania; ${ }^{30}$ Department of Allergy and Rheumatology, Nippon Medical School Graduate School of Medicine, Tokyo, Japan; ${ }^{31}$ Paris Descartes University, INSERM U1016, Sorbonne Paris Cité, Cochin Hospital, Paris, France

Background: Few small-sized observational studies have suggested that rituximab might be a promising treatment in systemic sclerosis (SSc)

Objectives: To evaluate the outcomes of SSc-patients receiving in routine care Rituximab

Methods: Retrospective longitudinal multicenter observational study which included SSc-patients treated with rituximab upon the decision of their physician within the framework of EUSTAR. We interrogated the participating centres and EUSTAR database to determine epidemiological and clinical characteristics, the indication for initiating the treatment, and the following parameters at baseline and at the last visit under treatment: modified Rodnan Skin Score (mRSS), joint, lung and gastrointestinal involvements, treatment, laboratory tests and safety events. Results: 248 patients were included: $70(28 \%)$ men, mean age: $51 \pm 13$ years, mean disease duration: $7 \pm 7$ years; $150(65 \%)$ had diffuse cutaneous-SSc, $54 \%$ were positive for anti-topoisomerase and $71 \%$ had lung fibrosis. Overlap disease was noticed in 62 patients $(26 \%)$ including 23 with rheumatoid arthritis. The indication for the treatment was lung involvement (56\%) followed by articular (42\%) and skin involvements (30\%). At baseline, 175 patients were treated with steroids and 132 with DMARDs. Mean follow-up was $2.4( \pm 1.9)$ years.

In the whole sample, mRSS decreased from $15 \pm 11$ to $10 \pm 8(p<0.01)$.

For SSc-patients treated for lung with baseline FVC $<70 \%, F V C$ improved from 56 $\pm 9 \%$ to $59 \pm 12 \% ; p=0.02$. In patients with articular involvement $(n=83)$, tender joint and swollen joint counts decreased from $9 \pm 7$ to $4 \pm 6$ and from $3 \pm 5$ to $1 \pm 3$, respectively $(\mathrm{p}<0.01)$.

In the whole population, 45 patients could stop steroids and mean dose decreased from $10 \mathrm{mg}$ to $7 \mathrm{mg}$ in the other.

During the follow-up, 78 (31\%) patients had side effects including 35 (14\%) with severe side effects leading to discontinuation of the treatment in $10 \%$. Six deaths were recorded (1 heart failure, 1 sepsis, 2 respiratory insufficiencies, 2 sudden deaths). 76 patients had infection, requiring hospitalisation in 20 patients.

Conclusions: In this study, skin, lung and joint involvement appeared to improve under rituximab. Infections and other severe adverse events were frequently

reported. A comparative study including control patients from EUSTAR centres is ongoing.

Disclosure of Interest: M. Elhai: None declared, O. Distler Grant/research sup port from: Actelion, Bayer, Boehringer Ingelheim, ChemomAb, espeRare foundation, Genentech/Roche, GSK, Inventiva, Lilly, medac, Medlmmune, Mitsubish Tanabe Pharma, Novartis, Pfizer, Sanofi, Sinoxa and UCB in the area of potential treatments of scleroderma and its complications, V. Smith : None declared, M. Matucci-Cerinic: None declared, J. J. Alegre-Sancho : None declared, M.-E. Truchetet: None declared, Y. Braun-Moscovici: None declared, F. lannone: None declared, F. Chotchaeva: None declared, A. Lescoat : None declared, E. Siegert None declared, I. Castellví: None declared, P. Airò : None declared, S. Vettori: None declared, E. Hachulla: None declared, A. Erler : None declared, L. Ananieva : None declared, M. Krusche: None declared, F. López-Longo : None declared, J. Distler : None declared, N. Hunzelmann : None declared, A.-M. Hoffmann-Vold None declared, V. Riccieri: None declared, V. Hsu: None declared, M. Pozzi: None declared, C. Ancuta : None declared, E. Rosato : None declared, C. Mihai: None declared, M. Kuwana: None declared, Y. Allanore Grant/research support from: Actelion, Bayer, Boehringer Ingelheim, ChemomAb, Genentech/Roche, Inventiva, Pfizer, Sanofi, Servier, in the area of potential treatments of scleroderma and its complications.

DOI: 10.1136/annrheumdis-2018-eular.6024

\section{OP0143 \\ REGIONAL GRAFTING OF AUTOLOGOUS ADIPOSE TISSUE IS EFFECTIVE IN INDUCING PROMPT HEALING OF INDOLENT DIGITAL ULCERS IN PATIENTS WITH SYSTEMIC SCLEROSIS: RESULTS OF A MONOCENTRIC RANDOMISED CONTROLLED STUDY}

N. Del Papa ${ }^{1}$, E. Zaccara ${ }^{1}$, W. Maglione ${ }^{1}$, G. Di Luca ${ }^{2}$, R. Andracco ${ }^{1}$, C. Vitali ${ }^{3}$. ${ }^{1}$ Dept. Rheumatology, ${ }^{2}$ UOS Chirurgia Vascolare, ASST G. Pini-CTO, Milano; ${ }^{3}$ Rheumatology Section, Villa San Giuseppe, Anzano del Parco (Como), Italy

Background: Adipose-derived stromal/stem cells (ADSCs) are believed to be pluripotent cells with characteristics similar to BMMSCs. Preliminary attempts of cell therapy with ADSCs have been carried out with the purpose of inducing ulcer healing in peripheral vascular impairment that can be observed in animal models and human conditions. In a recent pilot open study from our group it has been demonstrated that lipofilling with autologous adipose tissue-derived cell fractions, which are known to contain both ADSCs and a stromal/vascular cell omponent, was effective in inducing a prompt healing of long lasting digital ulcers (DU) localised in the fingertips of a small number of patients with Systemic Sclerosis (SSc). The DU healing was accompanied by the rapid disappearance of local ischaemic pain and evidence of a partial restoration of capillary bed in the involved digits when assessed by nailfold videocapillaroscopy (NVC).

Objectives: A randomised controlled trial (RCT) was performed to confirm preliminary uncontrolled data indicating that regional adipose tissue (AT) grafting (G) is effective in inducing DU healing in patients with SSc.

Methods: Patients with SSc, fulfilling the 2013 ACR/EULAR classification criteria and suffering from a DUs lasting for at least 6 weeks prior to enrolment time and showing no tendency to heal, were randomised to be blindly treated with AT-G or a sham procedure (SP). AT-G consisted of injection at the base of the finger with DU of $0.5-1 \mathrm{ml}$ of AT after centrifugation of fat aspirate from abdominal adipose tissue. SP consisted of a false liposuction followed by the injection of $0.5-1 \mathrm{ml}$ of $0.9 \%$ saline solution at the base of the affected finger. Weekly iloprost infusion $(0.5-2 \mathrm{ng} / \mathrm{Kg} / \mathrm{min}$ ), and calcium-channel blockers (oral nifedipine $20 \mathrm{mg}$ daily) were administered during the entire observation time to all of the patients enrolled in both arms of the study.

The primary end-point was to compare the cumulative prevalence of healed DUs in the two groups within the following 8 weeks. Secondary end points to be assessed were: (i) pain intensity modification (measured by VAS), and (ii) variation of the number of capillaries in the affected digits (recorded by nailfold videocapillaroscopy) in patients receiving AT-G compared to those who underwent SP. Results: AT-G and SP were performed in 25 and 13 patients, respectively. The two groups were comparable for age, gender, disease duration and SSc subtypes.

DU healing was observed in 23/25 and 1/13 patients treated with AT-G and SP, respectively $(p<0.0001)$. The 12 patients who received the unsuccessful SP underwent a rescue AT-G. Also in all of them DU healing was observed after 8 weeks of observation. It was noticeable that only in the patients treated with AT-G either a significant reduction of pain intensity or an increase of capillary numbers in the affected finger were recorded after both 4 and 8 weeks $(p<0.0001$ in all the comparisons).

Conclusions: This RCT strongly confirm previous preliminary and uncontrolled data indicating that AT-G may be a successful option for inducing improvemen and healing in ischaemic SS-related fingertip DUs that are resistant to more traditional therapeutic approaches.

Disclosure of Interest: None declared

DOI: 10.1136/annrheumdis-2018-eular.4801 